not to develop a live human or humananimal hybrid. The use of SCNT-related technology to treat mitochondrial diseases does not involve cloning, but it does raise the question of whether it is acceptable for children to have three genetic 'parents': the mother who donates the egg nucleus, the father who donates the sperm nucleus and another woman who donates the mitochondrial DNA. The UK Human Fertilisation and Embryology Authority recommended in March that the government authorize the use of this technique to help these patients. We agree with this judgement.

Such possibilities need careful consideration and public consultation. We believe that the scientific community, which was forced to engage in ethical discussions in the early stages of stem-cell biology, should lead the way. As a first step, scientific academies such as the US National Academy of Sciences or the Australian Academy of Science should organize symposia to foster debate on the ethical ramifications of recent advances and possible new breakthroughs. Scientists should also engage with the public and the broader medical community; for instance, by collaborating with patient advocate groups such as the UK Juvenile Diabetes Research Foundation, and health-care providers such as the UK National Health Service. This would enable scientists to keep abreast of people's concerns, and to inform stakeholders of the realistic benefits and limits of their research and the ethical challenges it may bring.

The potential benefits of stem-cell research are immense. Prospects for transformative treatments for conditions such as macular degeneration, type 1 diabetes or Parkinson's disease are now on the horizon. But without first convincing governments, the public, and funding and regulatory bodies that all the possibilities have been thought through and evaluated, headline-catching results could create a backlash that unnecessarily delays the tremendous potential benefits of cell therapies. - SEENEWS \& VIEWS P.174

\section{Martin Pera is at the University of}

Melbourne, Australia. Alan Trounson is at the California Institute for Regenerative Medicine, San Francisco, California, USA. e-mails:mpera@unimelb.edu.au; atrounson@cirm.ca.gov

1. Tachibana, M. et al. Cell 153, 1228-1238 (2013).

2. Scott, C. T., McCormick, J. B. \& Owen-Smith, J. Nature Biotechnol. 27, 696-697 (2009).

3. The International Stem Cell Initiative Nature Biotechnol. 29, 1132-1144 (2011).

4. Ronen, D. \& Benvenisty, N. Curr. Opin. Genet. Dev. 22, 444-449 (2012).

5. Hayashi, K. et al. Science 338, 971-975(2012).

6. Grieshammer, U., Shepard, K. A., Nigh, A. \& Trounson, A. O. Nature Biotechnol. 29, 701-705 (2011).

7. Narbonne, P., Miyamoto, K. \& Gurdon, J. B. Curr. Opin. Genet. Dev. 22, 450-458 (2012)

8. Tachibana, M. et al. Nature 493,627-631 (2013).

9. Paull, D. et al. Nature 493, 632-637(2013).

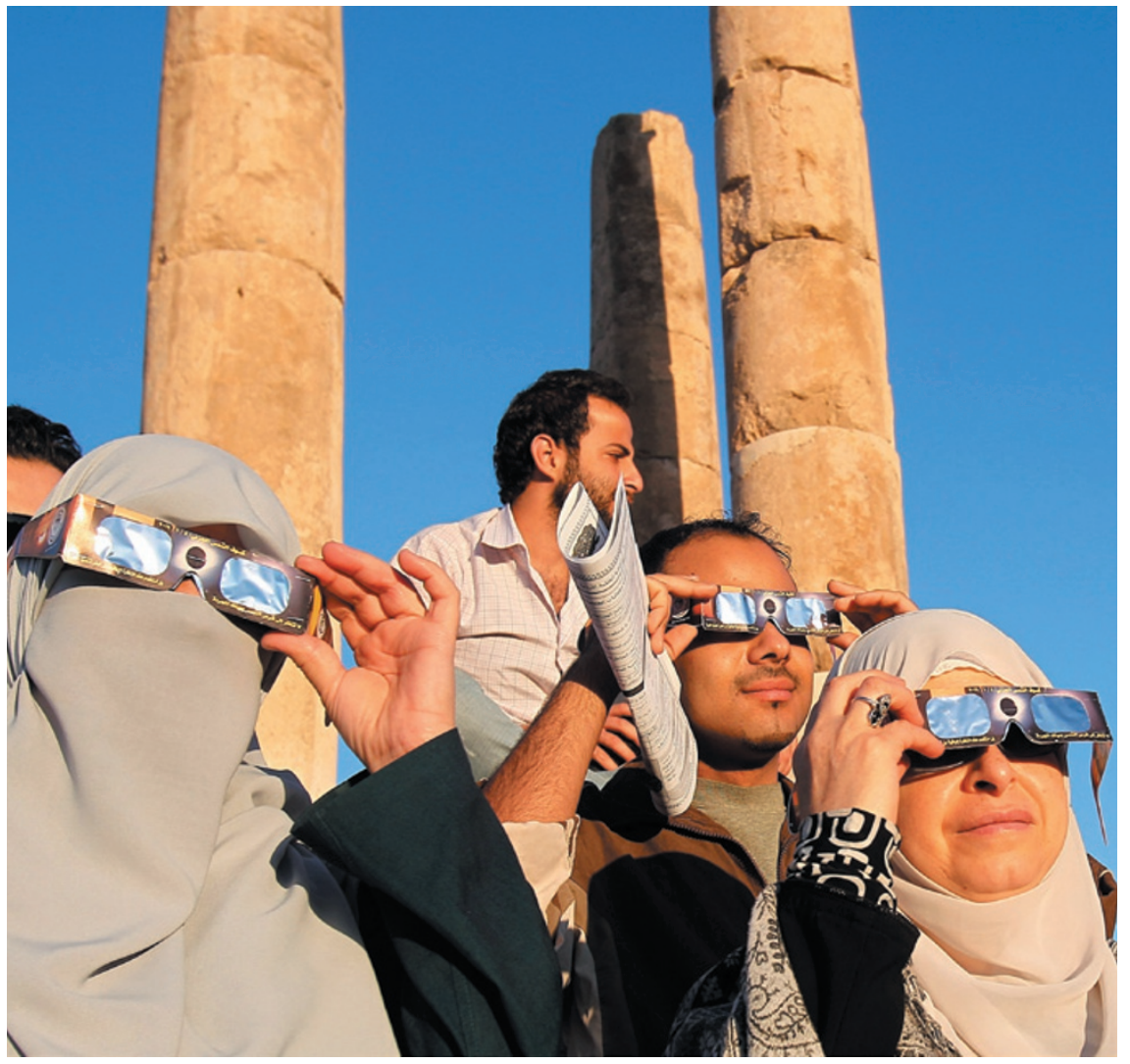

Observers in Amman, Jordan, watch the transit of Venus across the Sun in June 2012.

\title{
Time for an
}

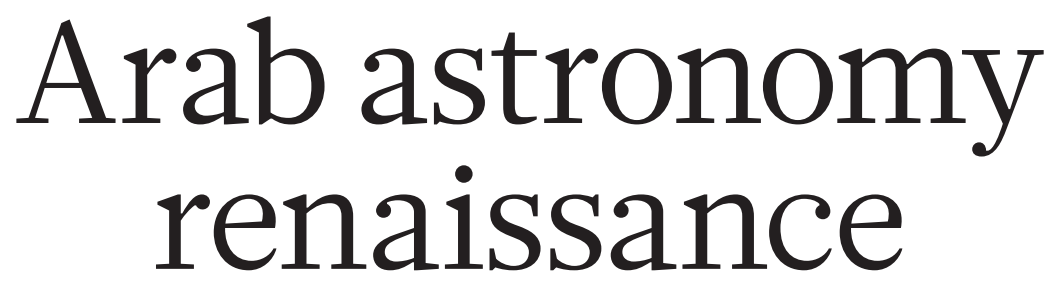

\section{Arab Muslim countries need a new generation of observatories to rejoin the forefront of the field, says Nidhal Guessoum.}

I

slamic astronomy enjoyed a golden age from the ninth to the sixteenth century AD. Great observatories in Baghdad, Damascus, Maragheh, Samarqand and Istanbul mapped the sky to set dates for religious and civil festivals and for astrology. Sophisticated calculations and models led to advances in mathematics.

Today, Arab astronomy barely registers on the world map. Scientific research is weak across the Arab world, and astronomy weaker still. Unlike countries of comparable gross domestic product per capita, such as Turkey, Israel and South Africa, most Arab nations are generating fewer than ten papers in the field each year, and these are hardly cited. Few sizeable telescopes are operational or planned.

The lagging state of astronomy is a paradox for a region where funding should not be a serious constraint, at least in the wealthier Gulf states. The region has several excellent observing locations above 2,000 metres that benefit from clear skies. Public fascination is strong, as shown by the many local amateur associations and large gatherings for astronomical events, such as eclipses, comet passages or the most recent transit of Venus across the Sun in June 2012. 
> In my view, astronomy research is being neglected because of the strongly utilitarian Arab Muslim approach to science ${ }^{1}$. Cultural principles, such as serving the people first, led Arab nations to build bases in the applied sciences in the second half of the twentieth century, including petrochemical engineering and pharmaceuticals. There was also a need for the region to develop its infrastructure quickly after the departure of colonial powers. Today, subjects such as theoretical physics are taught widely but are low cost and are considered low priority. Astronomy seems to require expensive buildings, equipment and technicians for little tangible return.

Another problem is the lack of expertise in the management of large scientific projects - an essential element if observatories and research centres are to operate effectively. The few large telescopes that have been built in the region in the past 50 years have been poorly run, are often inoperable and have produced few results.

I call on Arab countries to build a new generation of observatories. A few mediumsized telescopes (one- to two-metres in mirror diameter) costing a few tens of millions of dollars would allow Arab astronomers to join front-line research by searching for supernovae, the afterglows of $\gamma$-ray bursts, variable stars and extrasolar planets. Universities need to set up degree and international exchange programmes in astronomy to train and integrate the next generation of Arab astronomers. Such developments would galvanize academic and public interest in fundamental science across the region.

\section{A GOLDEN PAST}

Astronomy had a central place in society from the early times of Islamic civilization. In the early ninth century, a few decades after the founding of Baghdad as the capital of the new Muslim empire, the caliph al-Ma'mun (AD 786-833) ordered the erection of two observatories: Shammasiyya near Baghdad, and Jabal Qasiyun on the high outskirts of Damascus. Their main aim was to check solar and lunar data in old Greek and Indian tables, and to produce civil and religious calendars. Facilities included a quadrant made of marble with a radius of five metres to measure angles on the sky, and a sundial with a central gnomon - the column that casts the shadow - more than five metres high.

Islamic practice relies on astronomy for three purposes: computing prayer times for various locations and dates, which are based on the apparent motion of the Sun;

determining the direction to Mecca (the Qibla) for prayers; and establishing the dates for holy festivals, particularly Ramadan (the month of fasting) and Hajj (the pilgrimage), which are set by the observation of the thin crescent of the new Moon. All three still cause heated arguments among Muslim astronomers and scholars.

Historically, astronomy was also needed for navigation at sea and on land. Travellers and sailors learned that the arc of the Moon indicates the east-west line; the shortest shadow of a stick gives the north-south direction; the height of Polaris (the Pole Star) above the horizon gives the latitude of the place; and Mintaka, a star in Orion's belt, traces the celestial equator.

Muslim rulers were also guided by astrology, believing that some days were more propitious than others for mundane activities or stately decisions. Astronomers' ability to predict planetary motions and alignments, eclipses and new and full Moons was a powerful weapon in a ruler's arsenal. Courts had a resident astronomer, and mosques had a time-keeper (muwaqqit).

By the thirteenth century, rulers were erecting great observatories such as Maragheh (in present-day Iran), which was the largest in the world at the time. Astronomers and students from around the world used its sophisticated instruments, which included an armil-

(1)

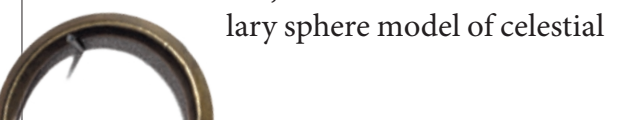

(1)
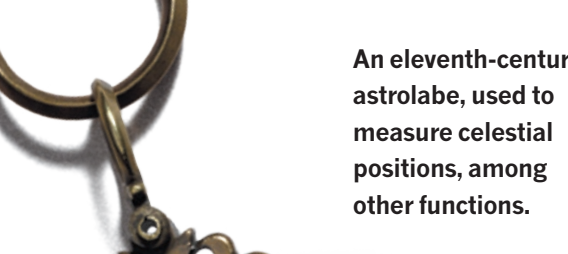

body motions several metres wide, as well as its library of 400,000 books. Theories developed there include the 'Tusi couple' that links linear and circular motion, which was developed by the astronomer Nasir al-Din al-Tusi in 1247, and later used by Nicolaus Copernicus in his geometry of planetary orbits.

In the fifteenth and sixteenth centuries, even more stunning observatories were built. In the Samarqand observatory (completed in 1429; now known as Ulugh Beg Observatory), a 30-metre-high building housed ten instruments. These included an armillary sphere; an azimuthal quadrant for measuring the horizontal angle of the star from the north; and a meridian arc with a 40 -metre radius, which measured celestial positions to within a few arcseconds. The Istanbul observatory, built in 1577, although smaller, also housed ten instruments and had 15 full-time astronomers ${ }^{2}$. Sophisticated tables giving the positions of stars, planets, the Sun and the Moon were produced in each.

Thus hundreds of stars and constellations have Arabic names, such as Altair, Deneb, Vega and Rigel. Today, more than 20 lunar craters bear the names of Muslim astronomers, including Alfraganus (al-Farghani), Albategnius (al-Battani) and Azophi (al-Sufi). The scholar Abu Rayhan al-Biruni (AD 973-1048) used astronomy and trigonometry to determine Earth's circumference to within $0.3 \%$ of today's accepted value. Muslim women participated too: in the tenth and eleventh centuries, Fatima of Madrid, daughter of the great Andalusian astronomer Maslama al-Majriti, helped her father to produce tables of star and planet positions. In the tenth century, Mariam of Syria was a skilled constructor of astrolabes for celestial surveying.

From the thirteenth century onwards, major centres of learning were lost, such as those in the Iberian territory of Al-Andalus, and conservative rulers and clergy accorded religious knowledge an ever higher place than worldly science. Universities disappeared and old places of learning became antiquated and disconnected from scientific developments in Europe. Observatories were seldom gifted rich, religious endowments (awqaf) and thus rarely continued for more than a few years or decades after their establishment.

Thus the era of great Islamic observatories came to an end in the later part of the sixteenth century, with the demise of the Ottoman empire and the rise of European science. The practice of astronomy, as with other areas of science at the time, depended on the good will of the caliph or patron. The Istanbul observatory was destroyed in 1580 , less than three years after its construction, by a new ruler who had been convinced by the religious 


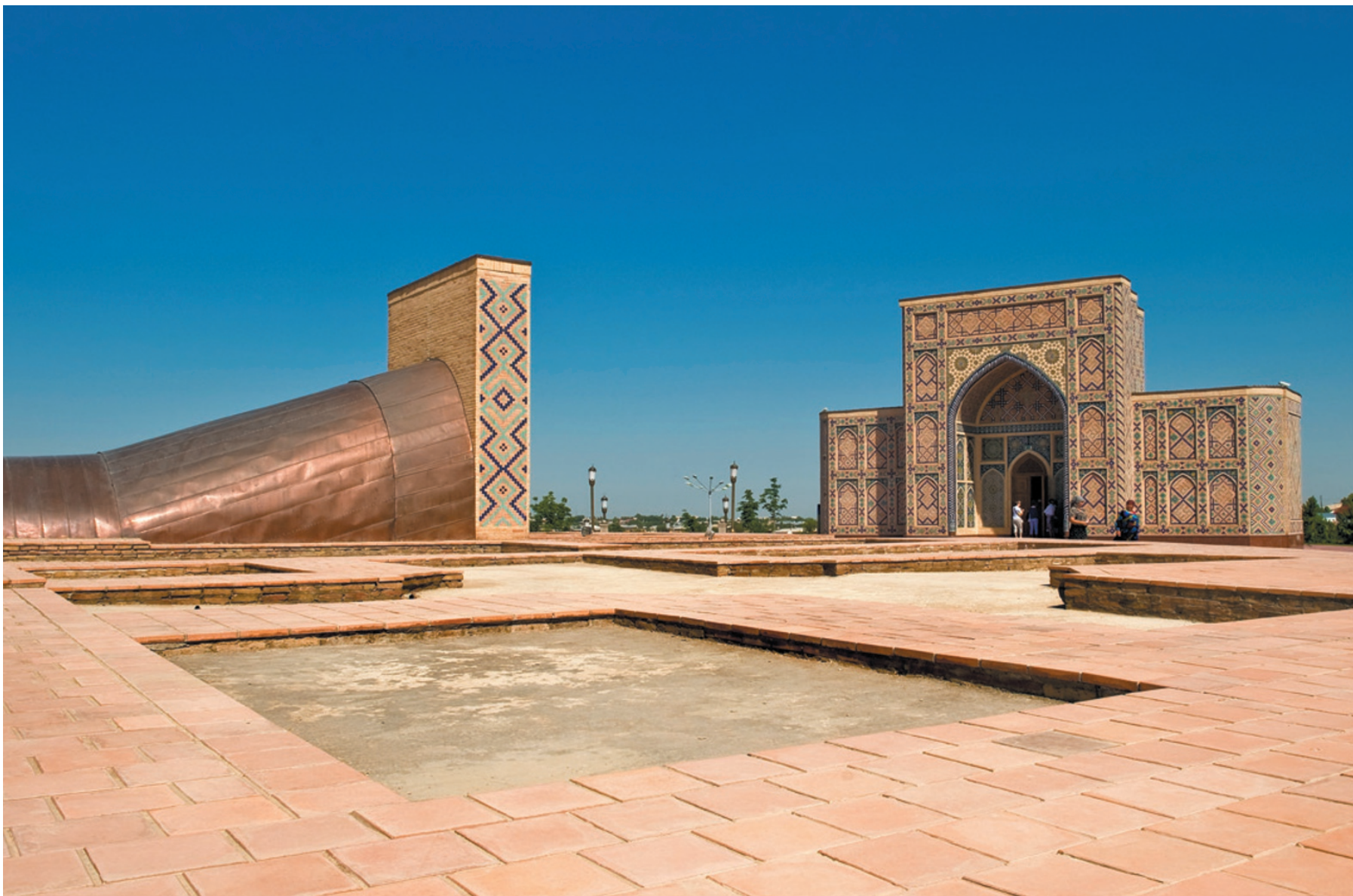

The Ulugh Beg Observatory in Samarqand, Uzbekistan, completed in the fifteenth century, was used by several famous Islamic astronomers.

establishment that "prying into the secrets of the heavens" was reprehensible and would trigger God's anger'.

As a result, no astronomy and little science were conducted in Muslim countries until the late-nineteenth century.

\section{ARAB ASTRONOMY TODAY}

Things got going again when European powers - Britain and France, in particular - colonized many parts of the Arab Muslim world, bringing modern ideas with them, but education to only a select few.

For instance, the Lee AstroPhysical Observatory in Lebanon, named after its British merchant patron, Henry Lee, was built in 1873 by Cornelius Van Alen Van Dyck, a passionate professor of astronomy at what later became the American University of Beirut. The observatory housed a 25-centimetre telescope, which worked well enough until the facility closed in 1980.

In 1891, French astronomers built an observatory on the hilltops overlooking Algiers; it contributed 1,260 photographic plates of the sky between 1891 and 1911 to the Astrographic Catalogue project, a large international effort to map star positions to a high degree of accuracy. In Egypt, the Helwan Observatory was built in the early twentieth century ${ }^{3,4}$; an astronomy department was established at Cairo University, and the country joined the International Astronomical Union (IAU) in 1925 (ref. 5).

Sadly, a world map of today's observatories shows just two medium-sized telescopes in Arab countries: Egypt and Algeria. By comparison, South Africa has half a dozen big observatories, including the South African Large Telescope (SALT) with an 11-metre primary mirror - the largest single optical telescope in the Southern Hemisphere. India has at least a dozen observatories, including the Indian Astronomical Observatory at Hanle, which houses a two-metre telescope.

The largest telescope to have graced the Arab world is the 1.88-metre instrument at Egypt's Kottamia Observatory, in the desert 75 kilometres outside Cairo. The telescope was inaugurated in May 1964, but for decades it was under-used or broken. Refurbished in the 1990s, Egyptian astronomers say that the telescope is now working, although few papers have resulted from it.

In Iraq, an ambitious plan to build a world-class observatory in the northern high mountains was launched in the 1980s, envisaging 3.5- and 1.25-metre telescopes, along with a 30 -metre radio telescope ${ }^{6}$. Wars and their resulting damage meant that the project was never finished. Plans to relaunch it have been aired, without progress.
In the past few years, two small observatories have been constructed in other parts of the Arab world. At an altitude of 2,750 metres, the Oukaimeden Observatory near Marrakesh in Morocco hosts a $50-\mathrm{cm}$ robotic telescope for asteroid and comet searches. It is run by the Cadi Ayyad University in Marrakesh in collaboration with Uranoscope de l'Ile de France (a French amateur astronomy association) and the Marrakesh Amateur Astronomy Association. Another observatory in Lebanon, built by Notre Dame University in Louaize, contains a $60-\mathrm{cm}$ telescope, which is expected to begin operating soon. Other Arab countries have smaller telescopes, with mirrors of $35-50 \mathrm{~cm}$.

Several Arab states have proposed one- to two-metre telescopes over the years, including Algeria, Libya, Oman, Saudi Arabia and the United Arab Emirates, but little progress has been seen.

\section{RESEARCH ANALYSIS}

To assess how badly astronomy research is suffering in the region, I compared publication and citation data for Arab nations with data from Iran, Israel, South Africa and Turkey (see 'Arab astronomy papers'). Arab astronomers published fewer papers and had fewer citations than astronomers in those 


\section{PUBLICATION DATA}

\section{Arab astronomy papers}

To assess the state of Arab astronomy research, I used the Thomson Reuters Web of Science to extract publication data for astronomy and astrophysics papers for each Arab country from 1 January 2000 to 31 December 2009. For comparison, I collected similar data for authors from Turkey, Iran, Israel and South Africa.

Because there were few papers for Arab countries, I examined them by hand and discarded ones on tangential and highly theoretical topics. The comparison countries had a greater number of papers, so I examined a random sample of 200 papers from each country and scaled the totals accordingly. For Arab countries, $40-50 \%$ of papers were excluded (reflecting the emphasis on theoretical work); for Iran, the percentage was $78 \%$; for Israel, 25\%; and for South Africa, 19\%.

The number of astronomy papers as a proportion of science papers for the Arab world is 3 per 1,000 (ranging from 1 for Qatar to 6 for Bahrain; Yemen has an abnormally high ratio owing to its very low science production). This is similar to Iran (2) and Turkey (3), but much lower than Israel (14) and South Africa (24), the proportions of which are similar to those of the United States, China, India, Japan, Brazil and Spain. (In these countries, the range is $10-25$ astronomy papers per 1,000 publications.)

The United Arab Emirates, for example, with a population of 8 million and a gross domestic product (GDP) per capita of US $\$ 46,000$ in 2011 , published 6,000 science publications over 10 years, but only 23 of those were in astronomy. Israel, with a similar population but a 30\% lower GDP per capita than the United Arab Emirates, published a total of 143,000 scientific papers, of which 1,500 were astronomy articles. Similarly, of the 13,000 science

\section{PAUCITY OF PAPERS}

Arab countries produce fewer astronomy papers than nations with similar GDPs.

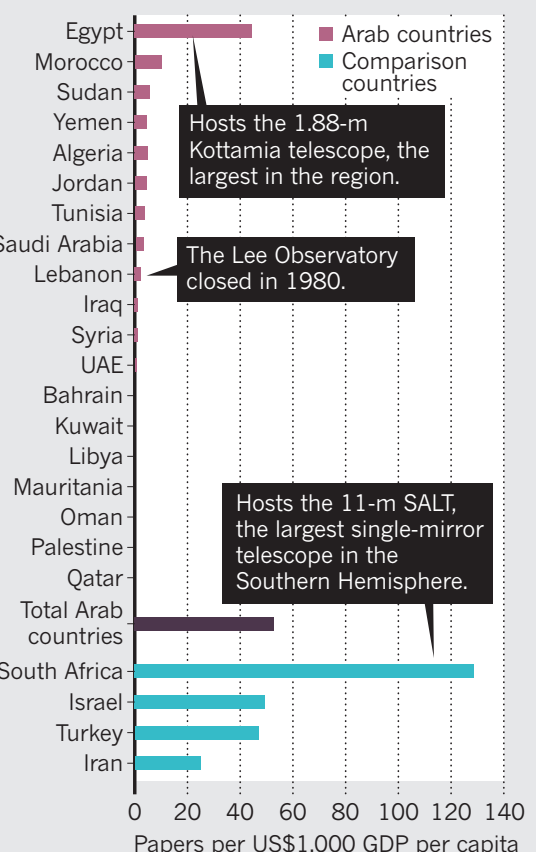

papers that were published by authors from Lebanon, which has a population of 4 million and a GDP per capita of $\$ 9,000$, just 19 were in astronomy.

The citation figures are even more striking. For publications in 2000-09, there were 1,507 citations for papers that had a first author from an Arab country and 1,596 for papers that include an author from an Arab country (but not a first author). This is a total of 3,103 citations, compared to 4,355 for Turkey, which contains one-fifth of the population of the Arab world. Israel's and South Africa's citation figures were 20 times and 9.5 times higher, respectively, than those of the Arab world. other four countries. The entire Arab world published fewer astronomy papers than Turkey alone, and substantially fewer than South Africa or Israel. Citation figures are worse: Arab astronomy papers were cited less often than Turkey's, South Africa's or Israel's.

As for degree programmes in astronomy or astrophysics at Arab universities, these can be counted on two hands. Small programmes exist in Egypt, Jordan, Lebanon, Saudi Arabia, Sudan and Algeria. Only a few dozen out of several million students major in astronomy or astrophysics at undergraduate or at master's level, and home-grown

\section{PhD students are rare.}

Conferences, colloquia and summer schools in astronomy are organized, but with modest academic impact. The Arab Union for Astronomy and Space Science (AUASS), a supranational organization linking professional astronomers and amateur associations of the Arab world, holds meetings every two years, but it has not published any proceedings.

\section{LOOKING FORWARD}

It is time for governments, funding agencies, science-advocacy organizations and universities of the Arab world to move beyond the utilitarian view of science and promote professional astronomy.

Large projects in this field can inspire the science and technology community, the education sector and the public, and shift attitudes towards basic research in general.

This can be done by accelerating efforts to build high-class observatories, with one- and two-metre telescopes in several countries; establishing astronomy programmes in all public universities; setting up exchange agreements with international institutions; and funding graduate students to pursue doctoral programmes at universities abroad.

The Arab world offers ample sites for high-quality observatories - several mountains have peaks higher than 3,000 metres. Mountain ranges in the Arabian peninsula that span the United Arab Emirates, Oman, Saudi Arabia and Yemen typically enjoy 200-250 clear nights a year. Peaks in the Sinai peninsula reach up to 2,600 metres, where at least 150 summer nights are clear. Similar suitable sites exist in several other countries, from Iraq to Morocco.

Rich Gulf states could work together to set up a world-class observatory. A facility would cost between US\$50 million and $\$ 100$ million, including equipment (a twometre telescope, photometer, spectrometer, fast computers and network links, and a weather station), buildings with work and meeting rooms, sleeping quarters and leisure areas, and local roads and infrastructure.

Arab universities should cooperate. Expert meetings should be convened to produce white papers on restarting astronomy in the region. These activities should be supported by international organizations such as the AUASS and the IAU to put pressure on governments. And it is essential that major Arab universities offer degree programmes in astrophysics.

Astronomy has a natural place high in the landscape of Arab Islamic culture. It must be brought back.

Nidhal Guessoum is professor of physics and astronomy at the American University of Sharjah, United Arab Emirates. e-mail:nguessoum@aus.edu

1. Guessoum, N. Nature Middle East http://dx.doi org/10/mrn (2012).

2. Sayili, S. The Observatory in Islam (Arno Press, 1981).

3. Hady, A. A. Adv. Space Res. 42, 1800-1805 (2008).

4. Hassan, S. M. 'Kottamia Telescope Upgrading' in Developing Basic Space Science World-Wide (eds Wamsteker, W., Albrecht, R. \& Haubold, H. J.) 237-240 (Springer, 2004).

5. Aiad, A. IAU Colloq. 105, 398-399 (1990).

6. Al-Naimiy, H. M. K. Proc. IAU Symp. 260, 429-437 (2011). 